\title{
Recent Advances in Prediction of Weld Residual Stress and Distortion - Part 2
}

\section{This paper reviews the recent advances in mitigation techniques that have been applied in the structure design, manufacturing, and postweld stages}

\author{
BY Y. P. YANG
}

\begin{abstract}
Weld residual stress can contribute to the reduction of structure lifetime and accelerate the formation of fatigue cracks, brittle fractures, or stress corrosion cracking. Distortion can have a significant impact on the dimensional accuracy of assembly, structure strength, and fabrication cost. In the past two decades, there have been many significant and exciting developments in the prediction and mitigation of weld residual stress and distortion. This paper reviews the recent advances in mitigation techniques that have been applied in the structure design, manufacturing, and postweld stages. The techniques used in the structure design stage include selecting the type of weld joint and weld groove, using balanced welding, determining appropriate plate thickness and stiffener spacing, and considering distortion compensation. Mitigation techniques used in the manufacturing stage include welding sequence optimization, reducing welding heating input, selecting low-transformation-temperature filler metals, prebending, precambering, constraints, trailing and stationary cooling, in-processing rolling, transient thermal tensioning, and additional heat sources. Postweld mitigation techniques include postweld heating and mechanical treatment. Finally, the remaining challenges and new development needs were discussed to guide future development in the field of mitigating weld residual stress and distortion.
\end{abstract}

\section{KEYWORDS}

- Numerical Analysis • Residual Stress • Distortion

- Finite Element Analysis

\section{Introduction}

Welding is one of the main joining technologies used for assembling metal parts in industries such as shipbuilding, bridge construction, oil and gas, automotive manufacturing, etc. Welding processes are characterized by local heating that leads to the melting of filler and base materials. The fast cooling after welding results in permanent plastic deformations that exist in the fusion zone vicinity and cause residual stress and distortion in the welded structure. Residual stresses combined with workload can significantly contribute to the reduction of structure lifetime and accelerate the formation of fatigue cracks, brittle fractures, or stress corrosion cracking (Refs. 1-5). Welds in thin-walled structures often produce residual stresses large enough to cause buckling, which can complicate distortion analysis and prediction (Refs. 6, 7). Moreover, the distortion can cause problems during the assembly of the structure. The elimination of residual stresses and dimensional imperfections using postweld thermal (Refs. 8, 9) or mechanical (Ref. 10) procedures requires additional financial costs, increases production time, and is often unsuitable because of the welded structure size and the location of assembly. To reduce weld residual stress and distortion as well as their consequences, it is necessary to know the shape and magnitudes of residual stresses and distortion as early as in the structure design phase. Numerical models have successfully been used in the prediction of weld residual stress and the development of mitigation techniques (Refs. 11-14) in the past two decades.

Weld residual stress and distortion can be controlled in the structure design, manufacturing, and postweld stages. Controlling weld residual stress and distortion during the product design stage is the most favorable stage because of the low cost and high effectiveness. Related research has been reviewed that includes selecting the type of weld joint and weld groove, using balanced welding, adjusting stiffener spacing, determining appropriate plate thickness, and using proper construction technique, including tack weld size and spacing. Distortion compensation, as an effective way to control distortion in the design stage, was introduced using a shipbuilding application example. 
Multiple mitigation techniques used in the manufacturing stage were reviewed that include welding sequence optimization, reducing welding heating input, low-transformation-temperature (LTT) filler metals, prebending, precambering, constraints, trailing and stationary cooling, inprocessing rolling, transient thermal tensioning (TTT), and additional heat sources. Trailing cooling, in-processing rolling, and TTT were mainly used for controlling buckling distortion on thin structures. Prebending and precambering techniques were mainly used for thick structures and cannot be used for buckling distortion control. The rest of the techniques can be used for both stable and unstable distortion control.

Postweld mitigation techniques, including postwelding rolling, postweld heat treatment (PWHT), and postweld mechanical treatment, were reviewed that are not favorable but have to do for certain applications. PWHT and mechanical treatment were utilized for reducing weld tensile residual stress or producing compressive residual stress to improve the fatigue performance of the welded joint. Postweld rolling on the weld can reduce both weld residual stress and distortion.

This paper focuses on the application of numerical modeling in the mitigation of weld residual stress and distortion. It is divided into two parts: mitigation techniques and prospects for future research. The mitigation techniques are classified into three categories based on controlling residual stress and technology in the structure design, manufacturing, and postweld stages. Most of the techniques are in the manufacturing stage category because controlling residual stress and distortion is limited in the design stage and not favorable in the postweld stage unless it is necessary. Each technique is discussed by emphasizing its principle and modeling examples. Finally, the remaining challenges and new development needs are discussed to guide the future development in the field of mitigating weld residual stress and distortion.

\section{Mitigation Techniques}

The negative cost, schedule, and performance impacts of welding distortion have led to the development of significant research on distortion mitigation methods. Advanced computational modeling has been a powerful tool to understand underlying mechanisms of weld residual stress and distortion and to evaluate reduction technologies. Weld residual stress and distortion can be controlled in the structure design stage, which is the best time, manufacturing stage, and postweld stage (Ref. 15). In-process control of welding distortion is more desirable than postwelding rectification from the point of manufacturing efficiency and cost. There are a large number of distortion control methods to choose from, with each targeting one or more fundamental modes of distortion (angular, bowing, buckling, etc.). The available methods generally fall into four broad categories (Ref. 16):

1. Component design. With the advancement of numerical modeling methods, it is possible to predict the effect of design selections on unit distortion potential. Through prudent selection of design details (e.g., weld size, stiffener spacing, cut-out locations, etc.), it is possible to increase stiffness and reduce distortion.
2. Welding heat input control. Welding heat input can have a major influence on all forms of distortion, particularly buckling distortion, and must be emphasized. Heat input may be reduced by improving fitting practice and optimizing welding processes as well as through training and vigilance of welders. Emerging welding processes - such as hybrid laser-arc welding (HLAW) or friction stir welding (FSW) may offer the opportunity to significantly reduce distortion, as compared with traditional arc welding processes.

3. Component restraint. Restraint can have a pronounced effect on reducing angular distortion, and, to a lesser extent, on buckling distortion. Effective restraint can be accomplished by using proper clamping devices, welding fixtures, welding sequences, or assembly sequences.

4. Active mitigation techniques. Some techniques are designed to counteract particular forms of distortion. Backbending, forced cooling, static thermal tensioning, and TTT are examples of active mitigation techniques. These approaches generally require capital investment in specialized equipment and optimization of the techniques for particular applications.

\section{Weld and Structure Design}

The increased use of thin plates, like in ships for highspeed operation, results in significantly increased distortion. It is favorable to control weld residual stress and distortion in the design stage. In general, important designrelated variables and practices include the type of weld joint and weld groove, using balanced welding, stiffener spacing, selecting the appropriate plate thickness, using the proper construction technique including tack weld size and spacing, and so on (Refs. 17, 18)

The thermo-mechanical model was used to simulate welding processes to study the effect of welding parameters and weld groove on temperature, residual stress, and distortion. Chen et al. (Ref. 19) investigated the effect of welding parameters and plate thickness on the temperature-time history in a butt joint with a Gaussian moving heat source model. Wei and Jiang (Ref. 20) conducted thermal elasticplastic analysis to evaluate the effect of the weld groove on residual stress and distortions in T-joint welding. The peak value of longitudinal and transverse residual stress in Kgroove welding is higher than those in no-groove welding. The influence of groove on distortion in T-joint welding is not significant.

$\mathrm{V}-$, K-, and X-groove types are commonly used grooves of butt-welded joints in heavy industry and shipbuilding. Ye et al. (Ref. 21) developed a 3D thermo-elastic-plastic model to investigate the influence of groove type on welding-induced residual stress and deformation in a SUS304 steel buttwelded joint. Experiments were carried out to validate the simulation model. The numerical results suggested that Xgroove is superior to $\mathrm{K}$ - and V-grooves for limiting angular distortion.

Properly designing the location, size, and spacing of tack welds is a highly effective approach to reduce distortion in welded structures because of the change in structure stiffness. Camilleri et al. (Ref. 22) numerically investigated the influence of different tack welding fabrication procedures on the final deformations of seam-welded plate structures. 
They proposed a fabrication procedure that leads to a minimal out-of-plane distortion. Abid and Siddique (Ref. 23) analyzed the effect of tack weld positions and root opening on welding distortions and residual stresses in a pipe flange joint.

Distortion compensation is a great way to control distortion in the design stage. Yang et al. (Refs. 24, 25) developed a weld-shrinkage data model that can be used to calculate weld shrinkage in ship production panels by inputting weld size and material information (Ref. 26). The weld-shrinkage values are included in the panel design so that the panels have the desired dimensions after welding. In addition, presetting is another method for distortion compensation. The design of a structure is altered in such a way that, after welding distortion, the preferred final shape will be achieved.

\section{Welding Sequence Optimization}

Welding sequence has a significant effect on the distortion of welded structures. The deformation adversely affects the subsequent fitup and alignment of the adjacent panels, resulting in loss of structural integrity. It is very costly and time consuming to optimize welding sequences to minimize distortion by experiment. Numerical simulation based on finite element (FE) modeling has been widely used to study the influence of welding sequences on the distribution of residual stress and distortion.

The most commonly used method to optimize welding sequence is a $3 \mathrm{D}$ thermo-mechanical analysis, especially for small welded joints (Refs. 27-33). For a large structure, a simplified analysis method such as the local-to-global method was used. Various algorithms for welding sequence optimization, such as a genetic algorithm and an artificial neural network, were attempted to reduce deformation (Refs. 34-36).

\section{Welded Joints}

Gannon et al. (Ref. 37) studied the effect of welding sequences on the distribution of residual stress and distortion of a flat-bar stiffener joined to a steel plate with sequentially coupled thermal and structural analyses. The effect of four welding sequences on the magnitude of residual stress and distortion in both the plate and the stiffener was investigated, and the effect on the ultimate strength of the stiffened plate under uniaxial compression was discussed. Mondal et al. (Ref. 38) studied the effect of four different welding sequences on a submerged arc welded (SAW) fillet joint on a stiffened plate panel. A FE model was developed to predict temperature, weld residual stress, and angular deformation. An optimal welding sequence was identified for minimizing the distortion on the panel.

Biswas et al. (Ref. 39) investigated the effect of welding sequence on the distortion pattern of large orthogonally stiffened panels used in ships and offshore structures. These panels primarily suffered from angular and buckling distortions. The extent of distortion depends on several parameters, such as welding speed, plate thickness, welding current, voltage, restraints applied to the job while welding, thermal history, and welding sequence. A FE mod- el was developed for studying the effect of these parameters on the distortion pattern and its magnitude on the fabrication of orthogonally stiffened plate panels. Park and An (Ref. 40) investigated the effect of welding sequence on fillet welding distortion. They proposed a new model based on the joint rigidity method to determine the welding sequence for minimizing welding distortion. Analysis and experiment of welding distortion on the test specimen with different stiffener distances were conducted. Analysis results developed a welding sequence that produced the minimum distortion.

\section{Welded Structures}

Rong et al. (Ref. 41) studied the deformation and residual stress of a large marine propeller nozzle induced by hybrid laser-arc girth welding using the local-to-global method. A T-joint was analyzed using thermo-elastic-plastic analysis to obtain the inherent strain. The combination form of a Gaussian surface and a conical heat source model was used to simulate the thermal flux of laser and arc power at the weld zone. An optimal welding sequence was then obtained to produce the lowest deformation and residual stress.

Zhang et al. (Ref. 42) developed a full-size FE model of a vacuum vessel to predict residual stress and distortions induced by multipass welding using ABAQUS. Three different gas tungsten arc welding (GTAW) sequences were simulated on this vessel. Sequence 1 resulted in the minimum weld residual stress and the lowest distortion and was recommended to weld the vacuum vessel.

Huang et al. (Ref. 43) investigated the effect of deck plate materials (American Bureau of Shipping Grade DH36 and HSLA-100 steel alloys) and welding sequences on residual stress distributions and distortion near an aircraft tie-down on a ship deck. Six different welding sequences, designed with multiple stops and starts to reduce locked-in residual stress, were analyzed. The best sequence was identified in terms of final residual stress distribution and the deck plate distortion. The optimized welding sequence had the lowest radial residual stresses among the studied six sequences, resulting in lower final deck plate distortion with similar hoop stresses and negligible axial stresses after welding. The radial residual stresses, acting perpendicular to the weld direction, are the most concerning because of their direct influence on the fatigue life of ship structures under sea-state cyclical and fluctuating environmental loads.

Wang et al. (Ref. 44) predicted and mitigated weldinginduced distortion during the fabrication of I-section welded structures in cantilever beams of jack-up drilling rigs using the inherent deformation method. First, welding inherent deformations were taken out from typical welded joints by conducting thermal-elastic-plastic FE analysis. Then, the inherent deformation was applied to the welding interfaces in the welded structure meshed with coarse shell elements. Elastic analysis was employed to predict distortion. Some mitigation practices such as application of inverse distortion, optimization of welding sequence, and constraint methods were conducted and examined. In particular, welding sequence strongly affected the final dimensional accuracy. 


\section{Reducing Welding Heat Input}

Numerical models have been developed and used in simulating welding processes to develop distortion control techniques. Low-heat input welding methods, intermittent welds, and HLAW were studied to investigate their effect on distortion.

\section{Select Low-Heat Input Welding Methods}

Colegrove et al. (Ref. 45) compared welds made by SAW, direct current gas metal arc welding (GMAW), pulsed GMAW (GMAW-P), cold metal transfer (CMT), autogenous laser, and HLAW on butt joints of 4-mm-thick DH36 plate. Autogenous laser and HLAW were found to produce the lowest distortion. GMAW-P and CMT were also good options to lower welding-induced distortion. Bhide et al. (Ref. 46) compared SAW, GMAW, and FSW in terms of buckling propensity on HSLA- 65 welded plates. Analyses of the longitudinal residual stresses and distortion measurements revealed that the FSW plate had buckling distortion, while the GMAW and SAW plates had angular and bowing distortions. Yang et al. (Ref. 47) conducted a numerical study to predict the distortion resulting from flux cored arc welding (FCAW) and HLAW on a butt-joined long plate of ship steel. It was found that FCAW produced three times higher distortion than HLAW.

\section{Control Distortion Using Intermittent Welds}

As a practical technique, the intermittent welding procedure was employed to decrease the magnitude of welding inherent deformation and sequentially avoid the occurrence of welding-induced buckling (Ref. 48). Analyses were conducted to predict welding-induced buckling distortion on a ship panel welded with continuous welds and with intermittent welds (Ref. 47). Angular distortion and buckling distortion were observed in the continuously welded panel. Small deformation (nonbuckling) was predicted in the intermittently welded panel. This study shows that intermittent welding is an effective method to control buckling distortion in thin ship-panel fabrication.

\section{Control Heat Input and Weld Size}

Distortion in a weld results from the expansion and contraction of the weld metal and adjacent base metal during the heating and cooling cycle of the welding process. Typically, high heat input or large weld size induced more weld shrinkages, leading to large distortion. Widespread overwelding causes severe plate buckling in shipbuilding during construction. For a 4-mm fillet weld, the total weld area in a doubled fillet weld is $16 \mathrm{~mm}^{2}$. If the weld size increases by 2 $\mathrm{mm}$, the weld area will be more than double, which induces additional costs that include filler metal, electricity, and the welder's labor hours. More importantly, the increased distortion due to overwelding will increase the difficulties of down-streaming fitting during structure assembly (Ref. 49).

Significant research has been conducted to develop a cost-effective solution for a welder who is not highly skilled to make smaller fillet welds. Zhang et al. (Ref. 50) and Liu et al. (Ref. 51) developed a 3D vision sensing system to measure the characteristic parameters of the weld pool in real time. The measured characteristic parameters were used to estimate the backside bead width with an adaptive neurofuzzy inference system as an emulation of the skilled welder. Dynamic experiments were conducted to establish the model that relates the backside bead width to the welding current and speed. Welding experiments confirmed the developed control system was effective in achieving the desired weld joint penetration under various disturbances and initial conditions. Additionally, Zhang et al. (Refs. 52, 53) proposed the use of a low-cost compact miniature sensor to measure position, orientation, and speed. This sensor can be encapsulated inside the welding torch to monitor its motion (or weld) for position, speed, angle, etc. The torch motion data can be used to ensure the torch movement by a human welder is in compliance with the welding procedure specification, such as proper weld size in ship production.

\section{LTT Filler Metals}

A concept was proposed by inducing compressive residual stresses from martensite transformation to reduce tensile residual stresses and improve fatigue life of the welded component (Ref. 54). Efforts were made to design LTT weld filler metals that can induce compressive residual stresses near the weld toe region via phase transformations (Ref. 55). The martensite start and finish temperatures are essential parameters in inducing compressive residual stresses. It is important that the martensite transformation begins at a lower temperature and finishes at a temperature just above the final temperature to which the final weld is expected to cool.

Wang et al. (Ref. 56) studied the effect of geometries on weld residual stress with LTT filler metals. A butt-welded plate and pipe were designed to have the same dimensions in the cross section perpendicular to the weld interface. A clear difference was found in these two joints. Longitudinal tensile stress in the weld zone was efficiently reduced in both joints, whereas longitudinal tensile stress was formed in the base metal near the weld zone in the pipe. A notably greater influence on transverse stress was found in the pipe than in the plate.

Azizpour et al. (Ref. 57) conducted 3D FE simulations with a coupled thermal-metallurgical-mechanical model using SYSWELD software to predict weld residual stresses for both a LTT filler metal and a conventional filler metal on a four-pass butt joint of Domex ${ }^{\circledR} 700 \mathrm{MC}$ steel plates. The analysis results, validated by hole-drilling stress measurement, indicated that the LTT filler metal reduced weld longitudinal tensile residual stress from 554 to $216 \mathrm{MPa}$ and transverse residual stress from tensile $156 \mathrm{MPa}$ to compressive $289 \mathrm{MPa}$.

Jiang et al. (Ref. 58) developed a thermo-elastic-plastic model coupled with solid-state phase transformation (SSPT) to investigate the effect of their designed LTT welding wire on the weld residual stresses in a $25-\mathrm{mm}$-thick ferrite steel plate. The analysis results, verified by neutron diffraction measurement, demonstrated that the LTT filler metals can significantly reduce the residual stress and even generate compressive residual stress in the weld zone. The higher in- 
terpass temperatures related to the microstructure evolution resulted in an increased region of compressive stress within the weldment, which was confirmed by Moat et al. (Ref. 59). Moreover, the longitudinal residual stress in the weld zone gradually changed to tension as the start temperature of martensitic transformation increased.

\section{Prebending and Precambering Techniques}

\section{Prebending Technique}

Prestaining is widely used to control welding-induced distortion in heavy industries. Before assembling welded structures, plates are bent into a permanent shape based on experience and experiment. After welding, welding-induced distortion makes the bent shape become straight. However, it is costly to determine the prebent shape and magnitudes. With the development of the weld modeling method, it is possible to determine the prebent shape and magnitudes by conducting a numerical modeling experiment. As an example, the prebending technique was used to mitigate distortion resulting from the J-groove circumferential fillet weld between a cylinder and a plate (Ref. 60). Before welding, the end edge of the plate was prebent to about $6-8 \mathrm{~mm}$ in the cylinder axle direction. After welding and machining, the prebent plate became almost flat.

\section{Precambering Technique}

Precambering is another technique in controlling welding-induced distortions in heavy industries. It is different than the prebending technique in that the welded structure is elastically bent by hydraulic tools to a certain shape just before welding in a specially designed fixture. Precambering techniques can be divided into four steps: 1) assembling plates into a component by tack welding, 2) using hydraulic tools to prebend the component to a certain shape, 3) welding the component, and 4) releasing precambering and fixtures. If the prebent shape and magnitudes are optimized, the component will have very small distortion after welding.

Advanced weld modeling procedures were used to assist the development of the precambering techniques for a large welded structure that was a component in earthmoving equipment. Several test precambering and welding analyses were performed by precambering the component into different shapes and magnitudes in the FE model (Ref. 60). Based on the model-predicted precambering shape and magnitude, the structure was welded by applying the precambering technique. After welding and releasing the precambering fixture, the final distortion was smaller than $1 \mathrm{~mm}$.

\section{Welding Constraints}

One of the practical methods for minimizing welding angular distortions is to use fixture/clamping during welding and releasing after welding. Traditionally, the fixed locations and releasing time were determined based on experience and experiment (Ref. 61). With the maturation of FE weld modeling methods, numerical models have been widely used to study the effect of welding constraints on weld residual stress and distortion (Refs. 62-68). Abid and Siddique (Ref. 62) conducted a 3D thermo-mechanical analysis to investigate the effect of mechanical constraints on welding distortions and residual stresses in a pipe flange joint. Liu and Zhang (Ref. 63) used a FE model to find the relationship between restraining force and moment and angular distortion. Chen and Li (Ref. 67) applied the combined 3D solid/ shell modeling method to investigate the influence of the mechanical restraints on the residual stresses and deflections of the large panel structures.

Gharib et al. (Ref. 69) studied the effect of clamping time on welding distortion of austenitic stainless steel 304L buttwelded joint by conducting thermo-mechanical analysis. The analysis results showed that the clamping changed the direction of bending and angular distortion (opposite to the one without clamping). Increasing clamping time reduced angular and bending distortion. Compared with the hot release mode (an immediate unclamping after welding), a 70\% reduction of angular and bending distortion was observed if the clamping was released after cooling to room temperature. The position of clamping has a significant effect on distortion reduction as well. If the clamping position is moved closer to the weld interface, the distortion can be further reduced. The results from Choobi et al. (Ref. 70) also revealed that clamping release time has a great influence on the distribution of residual stresses and angular distortion. Using clamping during welding and releasing after cooling to room temperature can significantly reduce the amount of angular distortion.

Wei and Deng (Ref. 71) as well as Deng et al. (Ref. 72) clarified the influence of external restraint on welding distortion in three different thin-plate steel welded structures by means of numerical simulation technology. A two-step computational approach was employed to simulate welding distortion in each welded structure. In the first step, the thermo-elastic-plastic FE method was used to obtain inherent deformation for each typical joint. In the second step, an elastic FE method based on inherent strain theory was used to compute welding deformation for three thin-plate panels with different thickness and shape. The effects of external restraint on welding deformation in a thin-plate panel with $5 \mathrm{~mm}$ thickness, a thin-plate panel with $10 \mathrm{~mm}$ thickness, and an asymmetric curved panel with $10 \mathrm{~mm}$ thickness were investigated.

\section{Trailing and Stationary Cooling}

Trailing cooling uses an intense heat sink trailing the welding heat source to create a characteristic valley-shaped temperature distribution, as shown in Fig. 1. Various researchers have used different cooling media: water, liquid nitrogen (Ref. 73), and solid $\mathrm{CO}_{2}$ (Ref. 74). Trailing cooling is an effective technique to control weld residual stress and distortion. Trailing cooling can also change the weld microstructure orientation and grain size to improve the weldjoint mechanical properties of high-strength aluminum alloys (Ref. 75). Trailing cooling has also been used to reduce transverse plastic strain behind the weld pool and eliminate hot cracking of high-strength aluminum alloys (Ref. 75). Trailing cooling with a stationary cooling source was pro- 

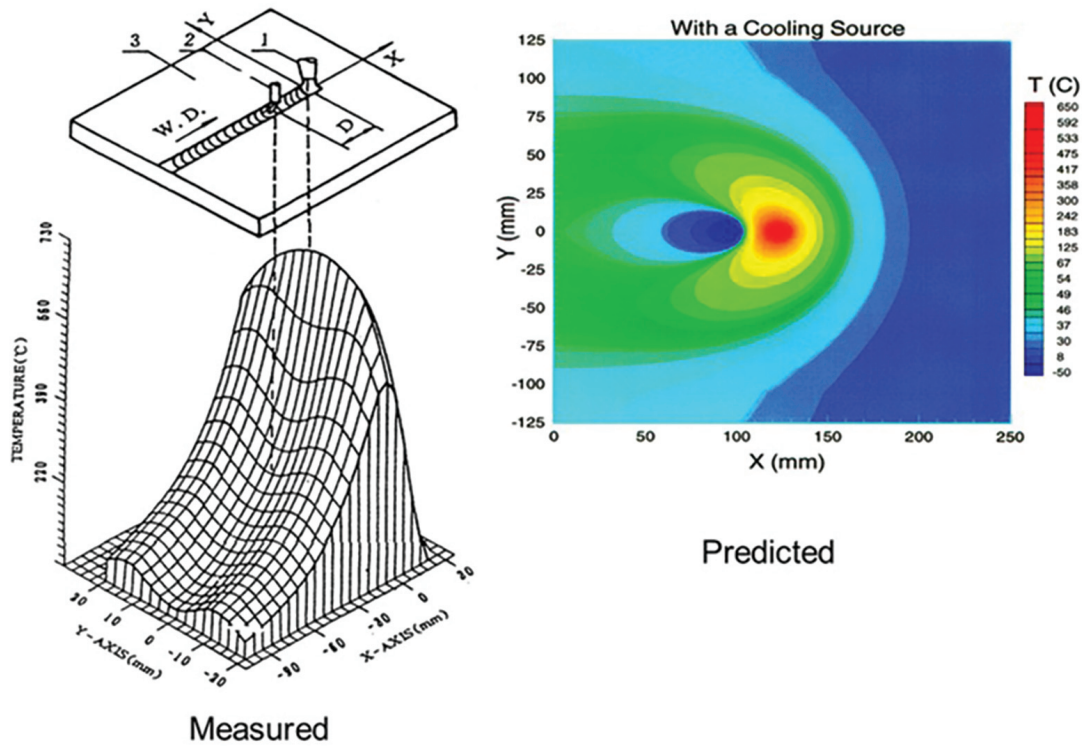

Predicted

Fig. 1 - Temperature distribution with trailing cooling.

posed by conducting FE analyses to prevent weld intersection cracking in a NASA hydrogen tank. Welding experiments on the small test panel confirmed the feasibility of using such a stationary cooling technique (Ref. 76).

Camilleri et al. (Ref. 77) used cryogenic $\mathrm{CO}_{2}$ cooling to reduce distortion on welded samples of a butt joint and a T-joint. A fully transient, uncoupled thermo-elastic-plastic model was conducted to investigate the feasible combination of welding process and cooling parameters. In butt-welded plates, a significant decrease in out-of-plane distortion was obtained when applying cryogenic cooling. In fillet-welded plates, cooling had much less effect on welding distortion.

Adak and Mandal (Ref. 78) developed a heat sinking method to control distortion in a butt joint through numerical modeling. Heat sinking has been achieved by circulating water through a channel clamped at the bottom surface of the plates undergoing welding. The results held a great promise for determining the heat sinking parameters for effectively controlling welding distortion.

Joo et al. (Ref. 79) investigated the effect of a trailing heat sink on welding residual stress and out-of-plane displacement using the FE analysis. This numerical simulation indicated that, compared to conventional welding, trailing heat sink welding first showed smaller deformation and residual stress. Secondly, it showed a significantly reduced out-of-plane displacement under optimal heat sink welding conditions. Lastly, it showed a reduced overall residual stress developed, although no significant differences were seen in the maximum values of welding residual stress. The reason for reduced weld deformation is that the effect of the heat sink could prevent the development of the plastic strain near the weld zone during the welding process.

Yang and Dong (Ref. 80) studied the mechanism of trailing cooling with transient thermal-elastic-plastic analysis. It was concluded the heat sink provided a stretching effect on the weld metal undergoing a rapid cooling so that the weld metal shrinkage could be reduced, which not only signifi- cantly reduced final residual stresses but also altered the overall distribution. Numerical modeling and experiments showed that three technological parameters - cooling distance, cooling intensity, and cooling area - determine the effectiveness of trailing cooling. This technique can effectively reduce buckling distortion on thin structures.

\section{In-Process and Postprocess Rolling}

The in-process rolling technique was first proposed by Yang and Dong (Ref. 80) with the help of numerical modeling. The process setup is illustrated in Fig. 2. During welding, a roller is placed at a distance behind the welding torch. By applying a force on the roller, a compressive plastic deformation is applied on the weld in contact with the roller in the through-thickness direction. The weld metal elongates in the lateral directions, resulting in reduced residual stresses. Some of the major rolling parameters are rolling force, roller width, and the distance between the welding torch and the roller. It should be pointed out that it is not necessary to have both the top roller and bottom roller. For instance, if a solid support can be used at the plate bottom, only the upper roller is needed. Since in-process rolling requires the design of special tooling, welding with electromagnetic trailing peening was developed, which can produce a similar effect as in-process rolling (Refs. 81, 82). In addition, to reduce residual stress and distortion, the in-process rolling technique can also improve weld microstructure and property (Ref. 83).

A recent study (Ref. 84) showed that in-process rolling cannot reduce the distortion on a laser-welded large panel. This is because laser welding typically uses a very fast travel speed, and the rolled location has a high temperature even with a long trailing distance. Residual stress continues to form during the subsequent cooling. Therefore, postprocess rolling was studied with numerical modeling. The analysis results indicate that postweld rolling gives a far greater re- 


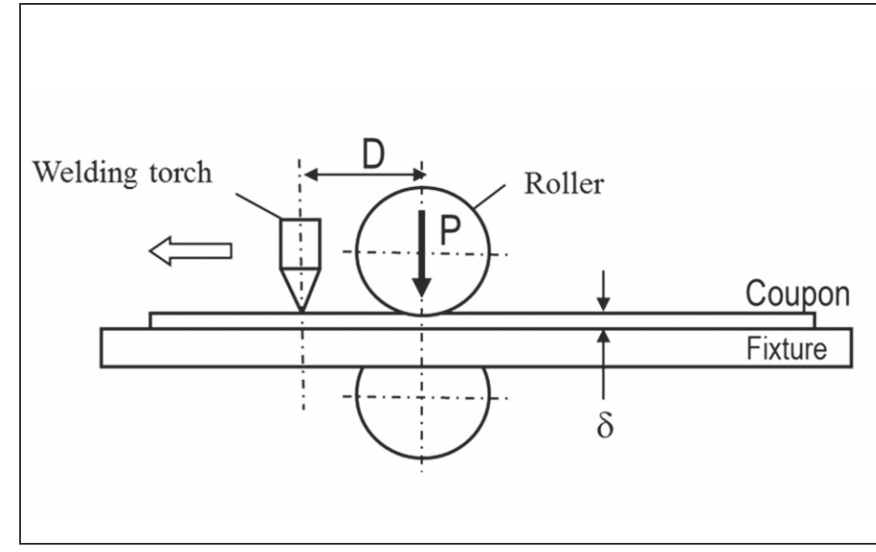

Fig. 2 - A concept of in-process rolling.

duction in the residual stress field and distortion.

Coules et al. (Refs. 85, 86) investigated the high-pressure rolling technique to eliminate weld residual stresses. Rolling was found to completely change the residual stress state in the weld, creating large compressive longitudinal residual stresses. It was effective for this purpose regardless of whether it was applied directly to the weld seam or to the regions on either side of it. Experiments showed that rolling applied at a high temperature, as welding is carried out, promotes the formation of acicular ferrite in the weld metal. This produces a weld material with a greater yield strength and hardness but a slightly reduced impact toughness compared to unrolled welds. Rolling of the weld metal once it has cooled instead causes work hardening.

Cozzolino et al. (Ref. 86) applied FE analysis to investigate two postweld rolling methods: rolling the weld bead directly with a single roller and rolling beside the weld bead with a dual flat roller. The models showed that both rolling techniques were able to induce compressive stress into the weld region. The distribution of stress was sensitive to the coefficients of friction between the workpiece, roller, and backing bar. High friction coefficients concentrated the plastic deformation and compressive stress within the center of the weld bead. Distortion can be eliminated by rolling; however, the experiments indicated that this was only achieved when applied to the weld bead directly.

He et al. (Ref. 88) proposed a stationary shoulder friction stir welding (SSFSW) method to control weld residual stress and distortion on a butt joint of 6005A-T6 aluminum alloy plates. A thermo-mechanical model was utilized to compare the residual stress distribution between conventional FSW and SSFSW. SSFSW was beneficial to decreasing the peak temperature of the stir zone (SZ) and then obtaining a narrower SZ. The peak residual stress produced by SSFSW was $50 \%$ lower than that by conventional FSW, and a narrower tensile stress region was attained by SSFSW. Moreover, the stationary shoulder applied a function of synchronous rolling during welding, which effectively controlled the distortion.

\section{Transient Thermal Tensioning}

Thermal tensioning approaches have been investigated since the mid-1990s as a means to reduce buckling distor-

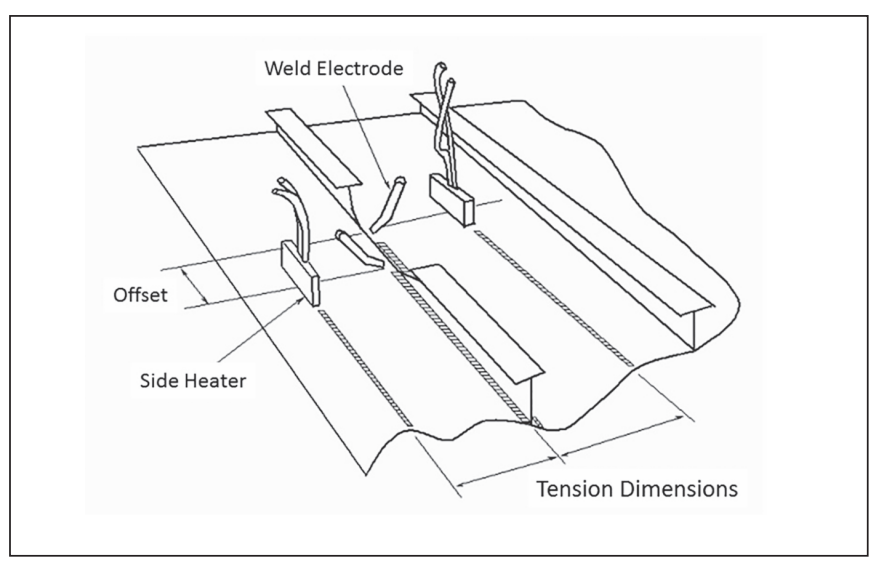

Fig. 3 - Second approach of TTT.

tion (Ref. 89). More recent studies (Refs. 90, 91) have focused specifically on the further development, demonstration, and application of TTT for the control of welding-induced buckling distortion of ship structures. Based on this work, TTT has been shown to be an effective and practical means of controlling buckling distortion in ship structures.

Two kinds of technical approaches were investigated during the development of the TTT process. The first approach developed early is to reduce weld tensile residual stress so that the compressive residual stress is reduced because of stress balances (Ref. 89). The second approach developed later is to directly work on the compressive stress by adding a tensile band in the compressive zone, which is easier to be implemented in production (Refs. 90, 91). Figure 3 shows the concept and experiment setup for the second approach of the thermal tensioning process. Two moving auxiliary heat sources are applied to narrow bands at some distance from the weld to induce the local tension zone where the weld compressive zones would normally exist. Oxyfuel flame heaters are carried along with the welding head. The heat source locally yields and shrinks an area in the plate in a similar manner. The process parameters include the size, location, travel speed, and intensity of the heat sources. Because the TTT heating apparatus are attached to the mechanized stiffener welding carriage, the welding speed dictates the TTT travel speed. In general, the thickness of the plate dictates the required intensity, which is adjusted by means of oxyfuel gas pressure and flow rate. The heat source must be concentrated enough to produce plasticity.

Figure 4 illustrates the principles of TTT with a sketch of longitudinal stress distributions (along the welding torch traveling direction). Without TTT, longitudinal tensile stress is produced near the fillet weld and balanced by compressive residual stress away from the weld. With TTT, two bands of residual tension stress are produced in the two auxiliary heating locations to counter compressive stress and minimize buckling. To confirm the theoretical stress distributions, a simple FE analysis was conducted with a set of TTT parameters on a DH36 plate with one Tee stiffener. Figure 5 shows the predicted longitudinal stress distribution without and with TTT. It was found that a tensile stress band was created in the flame torch heating location, which confirms the theoretical analysis. 
NO THERMAL TENSIONING, ONLY STIFFENER WELDS

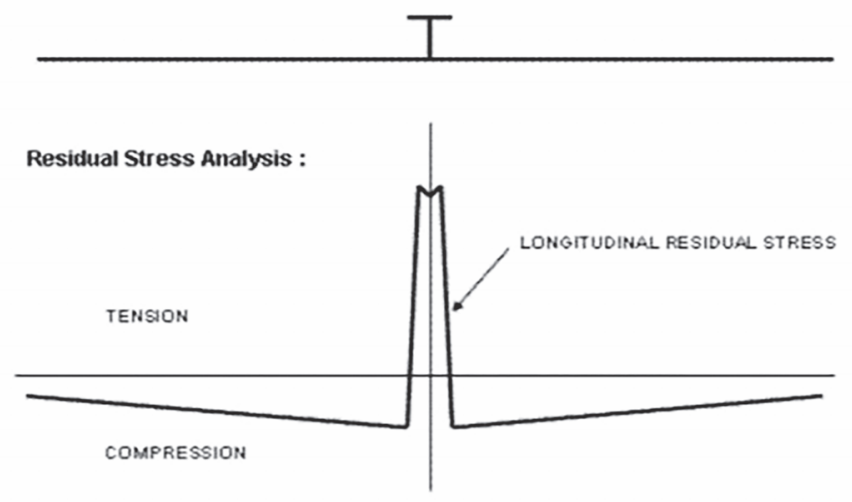

STIFFENER WELDS WITH THERMAL TENSIONING

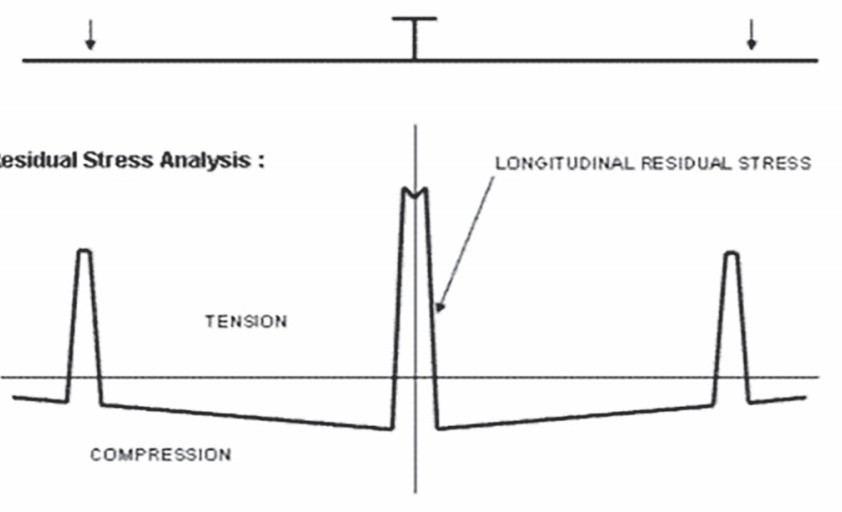

Fig. 4 - Stress distributions of $\Pi \pi$.

\section{Additional Heating Sources}

An in-process method for controlling welding distortion in fillet welds was developed by Mochizuki and Toyoda (Ref. 92). A schematic illustration of the proposed method is shown in Fig. 6. It particularly reduced angular distortion by performing reverse-side GTAW heating of the weld interface at a fixed distance ahead of GMAW during the welding process. Various heating conditions were examined by experiment and by the FE analysis to determine the appropriate conditions and study the mechanism by which welding distortion is reduced. It was consequently found that this mechanism is a result of two main effects: the GTAW heating effect on the reverse side, which produces the opposite angular distortion, and the preheating effect.

Pazooki et al. (Ref. 93) studied an in-process heating method to control welding-induced distortion in a large butt joint with experimental and numerical approaches. The additional heating sources were arranged on both sides of a weld. The left-hand side heating was conducted with a leading burner and a trailing burner. The right-hand side heating was conducted with two parallel burners. The mechanisms of distortion reduction in welding with additional heating are complex. The complicated nature of welding stress and strain fields is increased by the large number of parameters involved in welding with additional heating. In the region beneath and close to the burners, compressive residual stresses were reduced in welding with side heating compared with those of conventional welding of AH36. The essential feature of welding with side heating is the creation of a temperature peak at the location of the burners, which results in the creation of tensile residual stresses. This is very similar to the TTT technique.

Saurav and Biswas (Ref. 94) investigated the residual stresses and deformations with and without the effect of preheating by conducting experimental and 3D FE analysis of a butt joint welded with SAW on creep strength enhanced ferritic (CSEF) steel plate. The SSPT or austenitic-martensitic transformation characteristic of CSEF steel was considered in modeling. Thermal history, distortion, and residual stresses were predicted for as-welded and preheated weld models and validated with experimentally measured results. Deep-hole drilling techniques were carried out for residual stress measurement. The residual deformation was measured with a coordinate-measuring machine. It was observed that preheating effectively reduced the edge deflection and angular deformation values by 42 and 54\%, respectively. Preheating also exhibited a favorable effect on reducing longitudinal residual stress.

\section{Postweld Thermal/Mechanical Techniques}

Over the past several decades, numerous postweld thermal and mechanical techniques (i.e., heat treatment; grinding; GTAW dressing; ultrasonic impact; and hammer, shot, and laser peening) have been developed to improve mechanical and fatigue performance of weld joints. These treatments are generally classified into two different categories: geometry improvement and residual stress modification techniques. Geometry improvement techniques, such as GTAW dressing and grinding, focus on eliminating flaws and reducing the stress concentration of welded components. Residual stress modification techniques, like hammer, ultrasonic, laser, and shot peening, lay emphasis on introducing beneficial compressive residual stresses and improving residual stress distributions of welded joints (Refs. 95, 96).

\section{Postweld Heat Treatment}

PWHT is one of the most effective ways to relieve weld residual stress. Extensive numerical models have been conducted to understand the stress relief mechanism and determine the optimal process parameters. Hashmi et al. (Ref. 97) employed the FE method to model PWHT on a two-pass butt-joint welded SUS304 stainless steel pipe. First, the welding process was modeled, and then the stress distribution of the specimen was transferred to a second analysis for stress relaxation modeling. Norton law was used to investigate creep in the stress-relief process. Based on the model- 

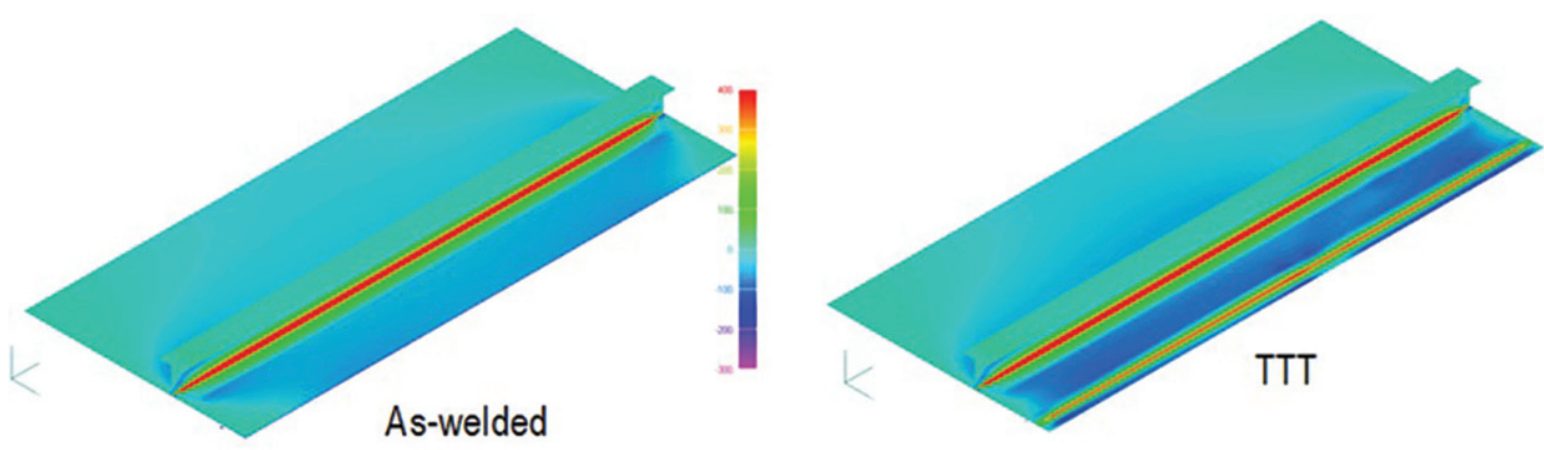

Fig. 5 - Longitudinal stress distributions after TाT.

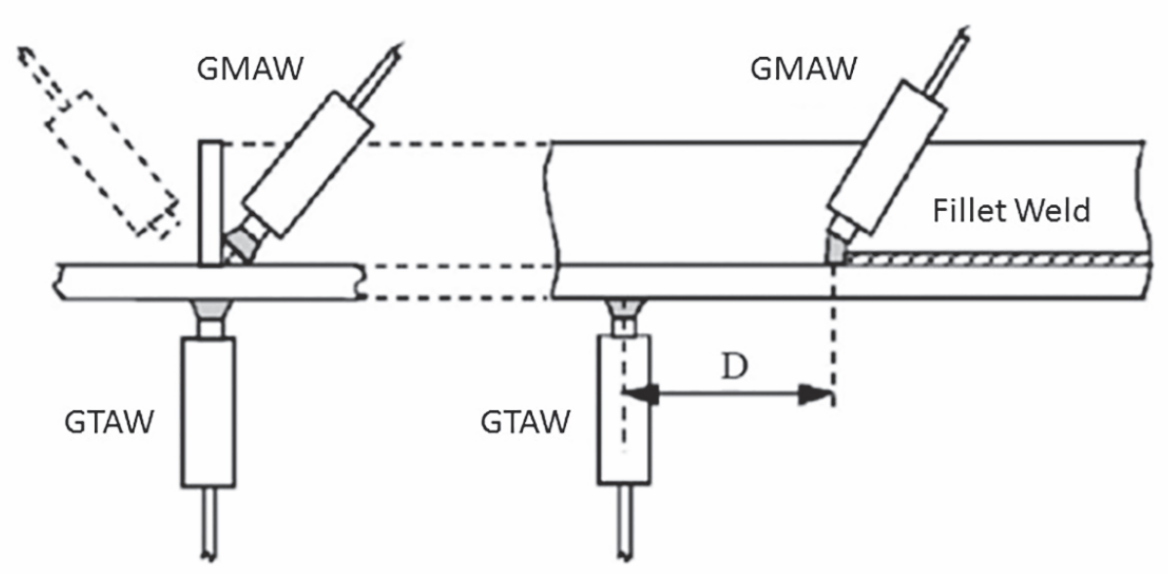

Fig. 6 - Schematic illustration of welding distortion control by reverse-side heating.

ing and experimental results, the tensile and compressive stress distributions were reduced.

Ren et al. (Ref. 98) took a thermo-metallurgical-mechanical coupled computational approach to analyze the residual stress distribution on 2.25Cr-1Mo welded pipe. A 3D FE model and moving heat source model were employed in simulation. The effects of SSPT, tempering, and creep were considered simultaneously. The simulation results showed that SSPT could induce an undulating stress profile and a large stress gradient in the welded zone. The stress gradient could be reduced during local PWHT while there were stress peaks at the edges of the heated region. The tempering effect could decrease the residual stress at the high-stress region by material softening and yielding. Creep caused a global transformation from elastic strain to plastic strain, which led to a macro-scale stress relaxation. Dong et al. (Ref. 99) used FE and analytical methods to study weld residual stress-relief mechanisms associated with furnace-based uniform PWHT. It was found that the most dominant stress relief mechanism is creep-strain-induced stress relaxation. A rapid creep strain development accompanied by a rapid residual stress reduction during the heating stage before reaching PWHT temperature was shown to contribute to most of the stress relief seen in the overall PWHT process, suggesting PWHT hold time can be significantly reduced as far as residual stress relief is concerned. Hirohata (Ref. 100) investigated a sheet-type ceramic heater as a portable heat source for PWHT of welded parts that can be treated in a furnace. Both an experiment and thermal-elasticplastic analysis were conducted to examine residual stress release on the welded parts between the deck plate and the trough rib. The effect of fatigue-life improvement by the stress release due to heat treatment was investigated.

\section{Postweld Mechanical Treatment}

Numerical models have been used to simulate postweld mechanical treatment processes, including ultrasonic impact treatment (UIT) as well as hammer, shot, and laser peening, to study their effect on weld residual stress. UIT has become increasingly popular because it reduces manpower requirements and is easy to apply. UIT uses needles or hammer-like rods to impact the welding surface/toe at a high ultrasonic frequency. It not only reduces the local stress concentration by modifying the weld toe geometry but also introduces compressive residual stresses by eliminating tensile residual stresses (Ref. 101).

Numerical models have been carried out to investigate the effect of the UIT on the weld residual stresses and fatigue performance of weld joints (Refs. 102-104). Foehrenbach et al. (Ref. 102) developed a computationally efficient approach to predict residual stresses induced by the UIT process using a commercial FE software package. It was found that compres- 
sive residual stresses up to a base material yield strength occurred after the UIT treatment. Guo et al. (Ref. 103) presented two 3D FE models to simulate the UIT process on 2024 aluminum alloy. In the single-impact mode, the effects of the initial impact velocity, pin size, and shape on the residual stress distributions were investigated. In the two-impact model, the effects of the second impact on the residual stress field induced by the first impact were investigated. Zheng et al. (Ref. 104) studied the effects of UIT on the residual stresses of 304L stainless steel weld joints. The UIT introduced beneficial compressive residual stresses at weld joints, and the maximum compressive stresses exceeded the compressive yield limit of 304L stainless steel. In addition, the effect of the UIT faded with the increasing depth at the weld toe. The depths of the ultrasonic impact treated compression layer of the T-joint and butt joint were up to 3 and $2 \mathrm{~mm}$, respectively.

\section{Prospect for Future Research}

\section{Mitigating Welding-Induced Distortion during Product Design}

Distortion compensation is a smart way to mitigate distortion during product design. Numerical models can be used to predict the distortion shape and magnitudes that could be included in the structure design. After welding, the structure could deform to the desired dimensions. There have been limited studies in this area. More research is needed to mature this technology.

\section{Structure Design with ICME Approach}

In the current welded structure design, a large safety factor is given to account for uncertainties, including weld residual stress and material changes after welding. This design approach increases structure weight, reduces fuel efficiency, and limits structure performance. An integrated computational materials engineering (ICME) approach should be applied into the welded structure design.

\section{Welding Optimization on Large and Complex Structures}

Welding process and sequence optimization are studied in small welded structures using a thermo-elastic-plastic analysis method. This method cannot be used for a large and complicated structure because of computational speed limitation. The inherent strain method could be an option for a large structure. But the thermal and mechanical interactions between welds are ignored in this analysis. These interactions are critical for welding-sequence studies.

\section{Control Distortion in the Entire Manufacturing Chain}

Distortion in a final product is an accumulation of all manufacturing processes. Welding is one of the processes that induces residual stress and distortion. However, incoming plate deformation during plate milling and transportation, material cutting, and forming also induce resid- ual stress and distortion. There have been limited studies in this area. More research is needed for industrial companies to apply this integrated technology in production.

\section{Integrated Weld Modeling Software with Robotic Welding}

Numerical models can be used to optimize welding sequence. The best welding sequence needs to input to a robot to conduct welding. An interface software is needed to automatically pass the welding sequence to a robot.

\section{Concluding Remarks}

Residual stresses and distortion existing in the weld can significantly impair the performance and reliability of welded structures. Advanced computational modeling has been a powerful tool to understand underlying mechanisms of weld residual stress and distortion as well as to help develop new mitigation technologies and improve existing technologies by optimizing process parameters. This paper reviewed the recent advancements and provided a prospect for future research. The review focused on discussing the theory of mitigation technologies and the numerical modeling application to optimize these technologies.

The mitigation technologies were classified into three categories based on the stage when they were applicable. In the product design stage, the most favorable stage because of low cost and high effectiveness, the mitigation techniques that could be applied included selecting the type of weld joint and weld groove, using balanced welding, determining appropriate plate thickness and stiffener spacing, using proper construction technique, and considering distortion compensation. In the manufacturing stage, mitigation techniques included welding sequence optimization, reducing welding heating input, LTT filler metals, prebending, precambering, constraints, trailing and stationary cooling, in-processing rolling, TTT, and additional heat sources. Trailing cooling, in-processing rolling, and TTT were mainly used for controlling buckling distortion on thin structures. Prebending and precambering techniques were mainly used for thick structures and cannot be used for buckling distortion control. In the postweld stage, mitigation techniques included postwelding rolling, postweld heat, and mechanical treatment.

\section{References}

1. Gannon, L., Liu, Y., Pegg, N., and Smith, M. J. 2013. Effect of three-dimensional welding-induced residual stress and distortion fields on strength and behavior of flat-bar stiffened panels. Ships and Offshore Structures 8(5): 565-578.

2. Paik, J. K., and Sohn, J. M. 2012. Effects of welding residual stresses on high tensile steel plate ultimate strength: Nonlinear finite element method investigations. Journal of Offshore Mechanics and Arctic Engineering 134(2): 021401-1-021401-6. DOI: 10.1115/1.4004510

3. McClung, R. C. 2007. A literature survey on the stability and significance of residual stresses during fatigue. Fatigue and Fracture of Engineering Materials and Structures 30(3): 173-205.

4. Brust, F. W., Dodds, R. H., Hobbs, J., Stoltz, B., and Wells, D. 
2019. Weld residual stress and fracture behavior of NASA layered pressure vessels. Proceedings of the ASME 2019 Pressure Vessels \& Piping Conference, PVP2019-94021. San Antonio, Tex. DOI: 10.1115/PVP2019-94021

5. Dong, P., and Brust, F. W. 2000. Welding residual stresses and effects on fracture in pressure vessel and piping components: A millennium review and beyond. J. Pressure Vessel Technol. 122(3): 329-338.

6. Dong, P. 2005. Residual stresses and distortions in welded structures: A perspective for engineering applications. Science and Technology of Welding and Joining 10(4): 389-398.

7. Ueda, Y., Murakawa, H., and Ma, N. 2012. Welding Deformation and Residual Stress Prevention. Elsevier Inc.

8. Dong, P., Song, S., and Zhang, J. 2014. Analysis of residual stress relief mechanisms in post-weld heat treatment. Int. J. Pres. Ves. Pip. 122(1): 6-14. DOI: 10.1016/j.ijpvp.2014.06.002

9. Peric, M., Garašic, I., Nižetic, S., and Dedic-Jandrek, H. 2018. Numerical analysis of longitudinal residual stresses and deflections in a T-joint welded structure using a local preheating technique. Energies 11(12): 3487. DOI: 10.3390/en11123487

10. Cozzolino, L. D., Coules, E., Colegrove, A. P., and Wen, S. 2017. Investigation of post-weld rolling methods to reduce residual stress and distortion. J. Mater. Process. Tech. 247: 243-256. DOI: 10.1016/j.jmatprotec.2017.04.018

11. Huang, T. D., Dong, P., Decan, L., Harwig, D., and Kumar R. 2004. Fabrication and engineering technology for lightweight ship structures, Part 1: Distortions and residual stresses in panel fabrication. Journal of Ship Production 20(1): 43-59.

12. Feng, Z. 2005. Processes and Mechanisms of Welding Residual Stress and Distortion. Woodhead Publishing.

13. Michaleris, P. 2011. Minimization of Welding Distortion and Buckling: Modelling and Implementation. Woodhead Publishing.

14. Coules, H. E. 2013. Contemporary approaches to reducing weld induced residual stress. Materials Science and Technology 29(1): 4-18.

15. Wu, C., and Kim, J.-W. 2020. Review on mitigation of welding-induced distortion based on FEM analysis. Journal of Welding and Joining 38(1): 56-66.

16. Conrardy, C., Huang, T. D., Harwig, D., Fong, P., Kvidahl, L., Evans, N., and Treaster, A. 2006. Practical welding techniques to minimize distortion in lightweight ship structures. J. Ship Prod. 22(4): 239-247. DOI: 10.5957/jsp.2006.22.4.239

17. Deng, D., and Murakawa, H. 2008. FEM prediction of buckling distortion induced by welding in thin plate panel structures. Comput. Mater. Sci. 43(4): 591-607. DOI: 10.1179/1743284712Y. 0000000106

18. Mandal, N. R., Prabu, S. K., and Kumar, S. 2014. Buckling of stiffened panels and its mitigation. Journal of Ship Production and Design 30(4): 201-206.

19. Chen, B. Q., Adak, M., and Soares, G. C. 2012. Numerical investigations to study the effect of weld parameters on the temperature-time history in steel plates. Maritime Engineering and Technology. Ed. T. A. Santos. CRC Press, pp. 285-293.

20. Wei, C. Y., and Jiang, W. G. 2020. Influence of welding groove on residual stress and distortion in T-joint weld. IOP Conference Series: Materials Science and Engineering 733: 012010. DOI: 10.1088/1757-899X/733/1/012010

21. Ye, Y., Cai, J., Jiang, X., Dai, D., and Deng, D. 2015. Influence of groove type on welding-induced residual stress, deformation and width of sensitization region in a SUS304 steel butt welded joint. Adv. Eng. Softw. 86: 39-48. DOI: 10.1016/j.advengsoft. 2015.04.001

22. Camilleri, D., Gray, T. G. F., and McPherson, N. 2010. Optimizing tack welding fabrication procedures using numerical finite element models. J. Ship Prod. 26(2): 117-134. DOI: 10.5957/ jspd.2010.26.2.117

23. Abid, M., and Siddique, M. 2005. Numerical simulation to study the effect of tack welds and root gap on welding deformations and residual stresses of a pipe-flange joint. Int. J. Press. Vessels Pip. 82(11): 860-871. DOI: 10.1016/j.ijpvp.2005.06.008

24. Yang, Y. P., Castner, H., Dull, R., Dydo, J. R., and Fanguy, D. 2013. Uniform-panel weld shrinkage data model for neat construction ship design engineering. Journal of Ship Production and Design 29(1): 1-16.

25. Yang, Y. P., Castner, H., Dull, R., Dydo, J., Huang, T. D., Fanguy, D., Dlugokecki, V., and Hepinstall, L. 2014. Complex-panel weld shrinkage data model for neat construction ship design engineering. Journal of Ship Production and Design 30(1): 1-24.

26. Yang, Y. P., Castner, H., Dull, R., Huang, T. D., and Fanguy, D. 2014. Material strength effect on weld shrinkage and distortion. Welding Journal 93(11): 421-s to 430-s.

27. Khoshroyan, A., and Darvazi, A. R. 2020. Effects of welding parameters and welding sequence on residual stress and distortion in Al6061-T6 aluminum alloy for T-shaped welded joint. Transactions of Nonferrous Metals Society of China 30(1): 76-89.

28. Keivani, R., Jahazi, M., Pham, T., Khodabandeh, A. R., and Afshar, M. R. 2014. Predicting residual stresses and distortion during multisequence welding of large size structures using FEM. Int. J. Adv. Manuf. Technol. 73(1-4): 409-19.

29. Hayajneh, M. T., Al-Dwairi, A. F., and Obeidat, S. F. 2018. Optimization and control of bending distortion of submerged arc welding I-beams. J. Constructional Steel Res. 142: 78-85. DOI: 10.1016/j.jcsr.2017.12.012

30. Islam, M., Buijk, A., Rais-Rohani, M., and Motoyama, K. 2014. Simulation-based numerical optimization of arc welding process for reduced distortion in welded structures. Finite Elements in Analysis Des. 84: 54-64.

31. Kumar, D. A., Mandal, N. R., and Mahapatra, M. M. 2011. A study on the effect of welding sequence in fabrication of large stiffened plate panels. J. Mar. Sci. Appl. 10(4): 429-436.

32. Fu, G. M., Lourenço, M. I., Duan, M. I., and Estefen, S. F. 2016. Influence of the welding sequence on residual stress and distortion of fillet welded structures. Mar. Struct. 46: 30-55. DOI: 10.1016/j.marstruc.2015.12.001

33. Chen, B., and Guedes Soares, C. 2016. Effect of welding sequence on temperature distribution, distortions, and residual stress on stiffened plates. Int. J. Adv. Manuf. Technol. 86: 31453156.

34. Hayajneh, M. T., Al-Dwairi, A. F., Lee, S., Seo, H. D., and Chung, H. 2018. Efficient welding distortion analysis method for large welded structures. J. Mater. Proc. Tech. 256: 36-50. DOI: 10.1016/j.jmatprotec.2018.01.043

35. Ansaripour, N., Heidari, A., and Eftekhari, S. A. 2020. Multi-objective optimization of residual stresses and distortion in submerged arc welding process using genetic algorithm and harmony search. Proceedings of the Institution of Mechanical Engineers, Part C: Journal of Mechanical Engineering Science 234(4). DOI: 10.1177/ 0954406219885977

36. Lostado, R., Martinez, R. F., MacDonald, B. J., and Villanueva, P. M. 2015. Combining soft computing techniques and the finite element method to design and optimize complex welded products. Integr. Comput.-Aid. E. 22(2): 153-70.

37. Gannon, L., Liu, Y., Pegg, N., and Smith, M. 2010. Effect of welding sequence on residual stress and distortion in flat-bar stiffened plates. Marine Structures 23(3): 385-404.

38. Mondal, A. K., Biswas, P., and Bag, S. 2017. Prediction of welding sequence induced thermal history and residual stresses and their effect on welding distortion. Welding in the World 61: 711-721.

39. Biswas, P., Kumar, D. A., and Mandal, N. R. 2011. A study on the effect of welding sequence in fabrication of large stiffened plate panels. Journal of Marine Science and Application 10(4): 429-436.

40. Park, J., and An, G. 2016. Effect of welding sequence to minimize fillet welding distortion in a ship's small component fabrication using joint rigidity method. Journal of Engineering Manufacture 
230(4): 643-653.

41. Rong, Y., Chang, Y., Xu, J., Huang, Y., Lei, T., and Wang, C. 2017. Numerical analysis of welding deformation and residual stress in marine propeller nozzle with hybrid laser-arc girth welds. International Journal of Pressure Vessels and Piping 158: 51-58. DOI: 10.1016/j.ijpvp.2017.10.007

42. Zhang, J., Yu, L., Liu, Y., Ma, Z., Li, H., Liu, C., Wu, J., Ma, J., and Li, Z. 2018. Analysis of the effect of tungsten inert gas welding sequences on residual stress and distortion of CFETR vacuum vessel using finite element simulations. Metals 8(11): 912. DOI: 10.3390/met8110912

43. Huang, T. D., Rucker, H. J., and Yang, Y. P. 2019. An ICME modeling application for the optimization of tie-down weld sequence in ship production. Journal of Ship Production and Design 35(2): 190-197.

44. Wang, J., Zhao, H., Zou, J., Zhou, H., and Wu, Z. 2017. Welding distortion prediction with elastic FE analysis and mitigation practice in the fabrication of cantilever beam component of jack-up drilling rig. Ocean Eng. 130: 25-39. DOI: 10.1016/ j.oceaneng.2016.11.059

45. Colegrove, P., Lkeagu, C., Thistlethwaite, A., Williams, S., Nagy, T., Suder, W., Steuwer, A., and Pirling, T. 2009. Welding process impact on residual stress and distortion. Science and Technology of Welding and Joining 14(8): 717-725.

46. Bhide, S. R., Michaleris, P., Posada, M., and Deloach, J. 2006. Comparison of buckling distortion propensity for SAW, GMAW, and FSW. Welding Journal 85(9): 189-s to 195-s.

47. Yang, Y. P., Kim, H., Mohr, W. C., Castner, H., Huang, T. D., and Fanguy, D. 2015. ICME applications in optimizing welding and thermal-forming processes. Proceedings of the $3^{\text {rd }}$ World Congress on Integrated Computational Materials Engineering (ICME), Wiley, May 31-June 4, Colorado Springs, Colo.

48. Wang, J., Yi, B., and Zhou, H. 2018. Framework of computational approach based on inherent deformation for welding buckling investigation during fabrication of lightweight ship panel. Ocean Engineering 157: 202-210. DOI: 10.1016/j.oceaneng. 2018.03.057

49. Huang, T. D., Harbison, M., and Kvidahl, L. Reduction of overwelding and distortion for naval surface combatants, Part 1 : Optimized weld sizing for lightweight ship structures. Journal of Ship Production and Design 30(4): 184-193. DOI: 10.5957/ jspd.2014.30.4.184

50. Zhang, W. J., Liu, Y. K., Wang, X., and Zhang, Y. 2012. Characterization of three-dimensional weld pool surface in gas tungsten arc welding. Welding Journal 91(7): 195-s to 203-s.

51. Liu, Y. K., and Zhang, Y. M. 2014. Model-based predictive control of weld penetration in gas tungsten arc welding. IEEE Transactions on Control Systems Technology 22(3): 955-966.

52. Zhang, Y. M., and Zhang, W. J. 2018. Measurement of threedimensional welding torch orientation for manual arc welding process. U.S. Patent 9,975,196.

53. Zhang, Y. M. 2020. Miniature torch speed sensor based adaptive manual arc welding. National Shipbuilding Research Program. Welding Technology Panel Meeting, Oak Ridge, Tenn.

54. Payares-Asprino, M. C., Katsumoto, H., and Liu, S. 2008. Effect of martensite start and finish temperature on residual stress development in structural steel welds. Welding Journal 87(11): 279 -s to 289 -s.

55. Alghamdi, T., and Liu, S. 2014. Low-transformationtemperature (LTT) welding consumables for residual stress management: Consumables development and testing qualification. Welding Journal 93(7): 243-s to 252-s.

56. Wang, X., Hu, L., Xu, Q., Chen, D., and San, S. T. 2016. Influence of martensitic transformation on welding residual stress in plates and pipes. Sci. Technol. Weld. Join. 22(6): 1-7.

57. Azizpour, K., Moshayedi, H., and Sattari-Far, I. 2019. Application of low transformation-temperature filler to reduce the resid- ual stresses in welded component. Journal of Mechanical Engineering and Sciences 13(1): 4536-4557.

58. Jiang, W., Chen, W., Woo, W., Tu, S. T., Zhang, X. C., and Em, V. 2018. Effects of low-temperature transformation and transformation-induced plasticity on weld residual stresses: $\mathrm{Nu}-$ merical study and neutron diffraction measurement. Materials \& Design 147(5): 65-79.

59. Moat, R. J., Ooi, S., Shirzadi, A. A., Dai, H., Mark, A. F., Bhadeshia, H. K. D. H., and Withers, P. J. 2018. Residual stress control of multipass welds using low transformation temperature fillers. Materials Science and Technology 34: 519-528. DOI: 10.1080/02670836.2017.1410954

60. Yang, Y. P., Brust, F. W., Cao, Z., Dong, Y., and Nanjundan, A. 2002. Welding-induced distortion control techniques in heavy industries. Proceedings of the $6^{\text {th }}$ International Conference on Trends in Welding Research. Pine Mountain, Ga.

61. Kohandehghan, A. R., and Serajzadeh, S. 2012. Experimental investigation into the effects of weld sequence and fixture on residual stresses in arc welding process. Journal of Materials Engineering and Performance 21(6): 892-899.

62. Abid, M., and Siddique, M. 2005. Numerical simulation of the effect of constraints on welding deformations and residual stresses in a pipe-flange joint. Model. and Simul. Mater. Sci. Eng. 13(6): 919. DOI: 10.1088/0965-0393/13/6/010

63. Liu, C., and Zhang, J. X. 2009. Numerical simulation of transient welding angular distortion with external restraints. Sci. Technol. Weld. Join. 14(1): 26-31.

64. Schenk, T., Doig, M., Esser, G., and Richardson, I. M. 2010. Influence of clamping support distance on distortion of welded $\mathrm{T}$ joints. Sci. Technol. Weld. Join. 15(7): 575-582. DOI: 10.1179/ 136217110X12731414739835

65. Adak, M., and Soares, G. C. 2014. Effects of different restraints on the weld-induced residual deformations and stresses in a steel plate. International Journal of Advanced Manufacturing Technology 71(1): 699-710.

66. Ma, N., Huang, H., and Murakawa, H. 2015. Effect of jig constraint position and pitch on welding deformation. Journal of Materials Processing Technology 221: 154-162. DOI: 10.1016/ j.jmatprotec.2015.02.022

67. Chen, Z., and Li, G. 2017. A study on the spring-back deflections and constraint forces of a bottom grillage cling welding. Ships Offshore Struc. 12(8): 1077-1085. DOI: 10.1080/ 17445302.2017.1313186

68. Venkatkumar, D., and Ravindran, D. 2019. Effect of boundary conditions on residual stresses and distortion in 316 stainless steel butt welded plate. High Temp. Mater. Proc. 38: 827-36. DOI: 10.1515/htmp-2019-0048

69. Gharib, A. R., Biglari, F. R., Shafaie, M., and Kokabi, A. H. 2019. Experimental and numerical investigation of fixture time on distortion of welded part. Int. J. Adv. Manuf. Technol. 104: 11211131.

70. Choobi, M. S., Haghpanahi, M., and Sedighi, M. 2010. Investigation of the effect of clamping on residual stresses and distortions in butt-welded plates. Scientia Iranica, Trans. B, Mech. Eng. 17(5): 387-394.

71. Wei, L., and Deng, D. 2018. Investigating the influence of external restraint on welding distortion in thin-plate welded structures by means of numerical simulation technology. Journal of Physics: Conference Series 1063: 012082. DOI: 10.1088/17426596/1063/1/012082

72. Deng, D., Liu, X., He, J., and Liang, W. 2016. Investigating the influence of external restraint on welding distortion in thinplate bead-on joint by means of numerical simulation and experiment. Int. J. Adv. Manuf. Technol. 82(5-8): 1049-1062.

73. Yang, Y. P., Babu, S. S., Kikel, J. M., and Brust, F. W. 2011. Investigation of weld crack mitigation techniques with advanced numerical modeling and experiment - Summary. Hot Cracking Phe- 
nomena in Welds III. Eds. J. Lippold, T. Bollinghaus, and C. E. Cross. pp. 353-365. Springer-Verlag Berlin Heidelberg.

74. Eisazadeh, H., Bunn, J., and Aidun, D. 2018. Exploring the cooling process for residual stress reduction in dissimilar welds. Welding Journal 97(11): 315-s to 319-s. DOI: 10.29391/ 2018.97.027

75. Yang, Y. P., Dong, P., and Zhang, J. 2000. A hot-cracking mitigation technique for welding high-strength aluminum alloy. Welding Journal 79(1): 9-s to 17-s.

76. Yang, Y. P., Dong, P., and Rogers, P. 2000. Heat sink welding for preventing hot cracking in Alloy 2195 intersection welds: A feasibility study. American Welding Society Convention. Chicago, Ill. NASA Technical Report, ntrs.nasa.gov/archive/nasacasi.ntrs.nasa.gov/ 20000080355.pdf

77. Camilleri, D., Gray, T. G. F., and Nash, D. H. 2008. Mitigation of welding distortion and residual stresses via cryogenic $\mathrm{CO}_{2}$ cooling - A numerical investigation. Proceeding of the $17^{\text {th }}$ International Conference on Computer Technology in Welding and Manufacturing, Cranfield University, UK.

78. Adak, M., and Mandal, N. R. 2010. Numerical and experimental study of mitigation of welding distortion. Applied Mathematical Modelling 34(1): 146-158. DOI: 10.1016/j.apm.2009.03.035

79. Joo, S. M., Bang, H. S., and Park, K. S. 2016. Numerical investigation on welding residual stress and out-of-plane displacement during the heat sink welding process of thin stainless steel sheets. Int. J. Precis. Eng. Manuf. 17(1): 65-72.

80. Yang, Y. P., and Dong, P. 2012. Buckling distortions and mitigation techniques for thin-section structures. Journal of Materials Engineering and Performance 21(2): 153-160.

81. Lu, M., Ma, Y., Zhao, J., Li, J., and Hao, J. 2009. Design and implementation of welding with electromagnetic trailing peening control circuit. 2009 International Conference on Measuring Technology and Mechatronics Automation: 361-364. DOI: 10.1109/ICMTMA. 2009.192

82. Xu, D., Liu, X., Wang, P., Yang, J., and Fang, H. 2009. New technique to control welding buckling distortion and residual stress with non-contact electromagnetic impact. Sci. Technol. Weld. Join. 14(8): 753-759.

83. Adams, T. E., Härtel, S., Hälsig, A., Awiszus, B., and Mayr, P. 2020. WeldForming: A new inline process combination to improve weld seam properties. Welding in the World 64: 601-610. DOI: 10.1007/s40194-020-00856-9

84. Yang, Y. P., Harris, I., Ritter, G., and Bishop, B. 2008. Finite element weld modeling for aerospace applications. $19^{\text {th }}$ Annual Advanced Aerospace Materials and Processes Conference \& Exhibition (AeroMat). Austin, Tex.

85. Coules, H. E., Colegrove, P., Cozzolino, L. D., and Wen, S. W. 2013. High pressure rolling of low carbon steel weld seams: Part 1 - Effects on mechanical properties and microstructure. Sci. Technol. Weld. Join. 18(1): 63-78.

86. Coules, H. E., Colegrove, P., Cozzolino, L. D., Wen, S. W., and Kelleher, J. F. 2013. High pressure rolling of low carbon steel weld seams: Part 2 - Roller geometry and residual stress. Sci. Technol. Weld. Join. 18(1): 84-90.

87. Cozzolino, L. D., Coules, H. E., Colegrove, P., and Wen, S. 2017. Investigation of post-weld rolling methods to reduce residual stress and distortion. Journal of Materials Processing Technology 247: 243-256. DOI: 10.1016/j.jmatprotec.2017.04.018

88. He, W., Liu, J., Hu, W., Wang, G., and Chen, W. 2019. Controlling residual stress and distortion of friction stir welding joint by external stationary shoulder. High Temperature Materials and Processes 38: 662-671. DOI: 10.1515/htmp-2019-0005

89. Michaleris, P., Dantzig, J. A., and Tortorelli, D. A. 1999. Minimization of welding residual stress and distortion in large struc- tures. Welding Journal 78(11): 361-s to 366-s.

90. Yang, Y. P., Dull, R., Conrardy, C., Porter, N., Dong, P., and Huang, T. D. 2008. Transient thermal tensioning and numerical modeling of thin steel ship panel structures. Journal of Ship Production 24(1): 37-49. DOI: 10.5957/jsp.2008.24.1.37

91. Yang, Y. P., Dull, R., and Conrardy, C. 2012. Transient thermal tensioning for control of stiffened panel buckling distortion. Australasian Welding Journal 57(4): 45-48.

92. Mochizuki, M., and Toyoda, M. 2007. Weld distortion control during welding process with reverse-side heating. J. Eng. Mater. Technol. 129(2): 265-270. DOI: 10.1115/1.2400275

93. Pazooki, A. M. A., Hermans, M. J. M., and Richardson, I. M. 2017. Control of welding distortion during gas metal arc welding of AH36 plates by stress engineering. Int. J. Adv. Manuf. Technol. 88(5-8): 1439-1457. DOI: 10.1115/1.2400275

94. Suman, S., and Biswas, P. 2020. Comparative study on SAW welding induced distortion and residual stresses of CSEF steel considering solid state phase transformation and preheating. Journal of Manufacturing Processes 51: 19-30. DOI: 10.1016/j.jmapro. 2020.01.012

95. Rakesh, R., Ghahremani, K., Walbridge, S., and Ince, A. 2016. Testing and fracture mechanics analysis of strength effects on the fatigue behavior of HFMI-treated welds. Weld World 60: 987-999.

96. Marquis, G. B., Mikkola, E., Yildirim, H. C., and Barsoum, Z 2013. Fatigue strength improvement of steel structures by highfrequency mechanical impact: Proposed fatigue assessment guidelines. Welding in the World 57: 803-822.

97. Hashmi, M. S. J., Yilbas, B. S., and Naher, S. 2009. Post welding heat treatment simulation in welded stainless steel pipe and comparison with experiment. Advanced Materials Research 83-86: 237-243. DOI: 10.4028/www.scientific.net/AMR.83-86.237

98. Ren, S., Li, S., Wang, Y., Deng, D., and Ma, N. 2019. Finite element analysis of residual stress in $2.25 \mathrm{Cr}$ - 1 Mo steel pipe during welding and heat treatment process. Journal of Manufacturing Processes 47: 110-118. DOI: 10.1016/j.jmapro.2019.09.019

99. Dong, P., Song, S., and Zhang, J. 2014. Analysis of residual stress relief mechanisms in post-weld heat treatment. Int. J. Press. Vess. Pip. 122: 6-14. DOI: 10.1016/j.ijpvp.2014.06.002

100. Hirohata, H. 2017. Effect of post weld heat treatment on steel plate deck with trough rib by portable heat source. Weld. World 61(6): 1225-1235.

101. Yu, J., Gou, G., Zhang, L., Zhang, W., Chen, H., and Yang, Y. P. 2016. Ultrasonic impact treatment to improve stress corrosion cracking resistance of welded joints of aluminum alloy. J. Mater. Eng. Perform. 25(7): 3046-3056.

102. Foehrenbach, V., Hardenecke, M., and Farajian, M. 2016. High frequency mechanical impact treatment (HFMI) for the fatigue improvement: Numerical and experimental investigations to describe the condition in the surface layer. Welding in the World 60: 749-755

103. Guo, C. B., Wang, Z. J., and Wang, D. P. 2015. Numerical analysis of the residual stress in ultrasonic impact treatment process with single-impact and two-impact models. Applied Surface Science 347: 596-601. DOI: 10.1016/j.apsusc.2015.04.128

104. Zheng, J., Ince, A., and Tang, L. 2018. Modeling and simulation of weld residual stresses and ultrasonic impact treatment of welded joints. Procedia Engineering 213: 36-47. DOI: 10.1016/ j.proeng.2018.02.005

YU-PING YANG (yupingyang@yahoo.com) was with the Edison Welding Institute, Columbus, Ohio, at the time this review was conducted. 